Anson S \& Turner K (2009) Rebound and disinvestment effects in refined oil consumption and supply resulting from an increase in energy efficiency in the Scottish commercial transport sector, Energy Policy, 37 (9), pp. 3608-3620.

This is the peer reviewed version of this article

NOTICE: this is the author's version of a work that was accepted for publication in Energy Policy. Changes resulting from the publishing process, such as peer review, editing, corrections, structural formatting, and other quality control mechanisms may not be reflected in this document. Changes may have been made to this work since it was submitted for publication. A definitive version was subsequently published in Energy Policy, [VOL 37, ISSUE 9, (2009)] DOI http://dx.doi.org/10.1016/j.enpol.2009.04.035 


\title{
Rebound and disinvestment effects in refined oil consumption and supply resulting from an increase in energy efficiency in the Scottish commercial transport sector
}

Sam Anson ${ }^{\mathrm{a}}$ and Karen Turner ${ }^{\mathrm{b}}$

\section{a. Scottish Government Transport Directorate ${ }^{1}$}

b. Department of Economics, University of Strathclyde

* Corresponding author: Department of Economics, University of Strathclyde, Sir William Duncan Building, 130 Rottenrow, Glasgow G4 OGE. Tel: 44(0)141 $5483864 . \quad$ E-mail: karen.turner@strath.ac.uk

\begin{abstract}
In this paper we use an energy-economy-environment computable general equilibrium (CGE) model of the Scottish economy to examine the impacts of an exogenous increase in energy augmenting technological progress in the domestic commercial Transport sector on the supply and use of energy. We focus our analysis on Scottish refined oil, as the main type of energy input used in commercial transport activity. We find that a 5\% increase in energy efficiency in the commercial Transport sector leads to rebound effects in the use of oil-based energy commodities in all time periods, in the target sector and at the economy-wide level. However, our results also suggest that such an efficiency improvement may cause a contraction in capacity in the Scottish oil supply sector. This 'disinvestment effect' acts as a constraint on the size of rebound effects. However, the magnitude of rebound effects and presence of the disinvestment effect in the simulations conducted here are sensitive to the specification of key elasticities of substitution in the nested production function for the target sector, particularly the substitutability of energy for non-energy intermediate inputs to production.
\end{abstract}

Keywords: general equilibrium, energy efficiency, rebound effects

JEL D57, D58, R15, Q41, Q43

\footnotetext{
${ }^{1}$ All views and opinions expressed in this paper are those of the individual authors and do not necessarily reflect the stance of the Scottish Government.
} 


\section{Acknowledgements}

The research reported in this paper develops work carried out by Sam Anson for his MSc dissertation (to meet the requirements of MSc Economic Management and Policy at the University of Strathclyde) under the supervision of Karen Turner, whose work on this paper has been funded by the ESRC under the First Grants Initiative (Grant reference: RES-061-25-0010). We are indebted to colleagues on the regional and energy modelling teams at the Fraser of Allander Institute, Department of Economics at the University of Strathclyde - namely Peter McGregor, Kim Swales and Grant Allan - for their ongoing work on developing the AMOSENVI modelling framework employed here. Karen Turner also acknowledges the aforementioned colleagues, and Nick Hanley, Department of Economics, University of Stirling, as co-authors on previous work (under previous funding by ESRC and under the EPSRC Supergen Marine Consortium, Grant reference: EP/E040136/1) investigating rebound effects in Scotland and the UK, upon which the research reported here builds. We are also grateful to participants at the International Input Output Association Meeting on Managing the Environment (Seville, Spain, July 2008) and to Steve Sorrell at the UK Energy Research Centre (UKERC) and Harry Saunders (Decision Processes Incorporated, California) for feedback, comments and advice on previous work investigating rebound and disinvestment effects. 


\section{Introduction}

In recent years there has been increasing interest in both the academic and policy arenas regarding what have come to be known as "rebound" and "backfire" effects (Jevons, 1865; Khazzoom 1980; Brookes 1990; Herring, 1999; Birol and Keppler, 2000; Saunders, 1992, 2000a,b; Schipper, 2000). Rebound effects result from the impact of increased efficiency in the use of energy on effective energy prices (price of energy per unit of production or consumption) and on actual energy prices (where there is domestic energy supply). Reductions in effective and actual energy prices lead to positive substitution, output/competitiveness, composition and income effects that act to offset the decreases in energy consumption that accompany pure efficiency effects. Such effects are general rather than partial equilibrium in nature and their magnitude depends on the degree of price responsiveness of direct and derived energy demands throughout the economy in question. As a result, applied or computable general equilibrium (CGE) models have been increasingly employed for empirical analysis of conditions under which rebound effects are likely to occur in response to increases in energy efficiency.

The study of rebound effects is, however, a relatively new area. A recent report by the UK Energy Research Centre (Sorrell, 2007) identifies only eight CGE models that have been used to assess the economic and environmental impacts of an energy efficiency improvement. Of the 10 key papers that are based upon these: Semboja (1994) looks at the effects of an increase in energy efficiency on the Kenyan economy; Dufournaud et al (1994) asses the impact of reduced household consumption of wood in the Sudan; Vikstrom (2004) conducts a historical CGE investigation on the rebound effect in the Swedish economy; Washida (2004) looks at an economy-wide energy efficiency increase in Japan; Glomsrød and Taojuan (2005) study the impact of coal cleaning in China; Grepperud and Rasmussen (2004) examine energy efficiency increases in a number of individual sectors in Norway; Hanley et al (2006) use regional CGE analysis to assess the impact of an energy efficiency increase in production in Scotland while Allan et al (2007) carry out a similar analyses for the UK. Hanley et al (2009) develop upon their earlier paper by doing sensitivity analysis around key parameters to clarify the theoretical conditions under which rebound and backfire effects exist in Scotland. Turner (2008, 2009) expands upon the Hanley et al $(2006,2009)$ and Allan et al (2007) studies by conducting systematic sensitivity analysis on the relative price sensitivity required to induce rebound effects in the Scottish regional and UK national economies. Turner's $(2008,2009)$ analysis also highlights the issue of potential disinvestment effects in domestic energy supply sectors in circumstances where direct and derived demands for energy are not sufficiently responsive to prevent falling prices from leading to reduced profitability (and contraction in capital stocks) in these sectors. 
Of the ten rebound papers cited above, eight have been published in the last four years, reflecting the fact that this area of economic study is still very new and, as such, is continuously developing. This is also demonstrated by the wide variation within these models of important assumptions regarding factors such as the specification of the production function and the treatment of energy within it; the elasticity of substitution between inputs; capital closure; labour market closure; the extent to which government expenditure is recycled; methods used to simulate energy efficiency improvements; and sectors/activities targeted with efficiency improvements. Sorrell (2007) and Allan et al (2008a) provide reviews.

This paper provides another empirical application of CGE analysis to the issues of energy efficiency and rebound effects. The AMOSENVI model of Scotland is the same one used in Hanley et al (2006, 2009) and Turner (2008). The reader is referred to these papers for details of model specification. However, a brief model overview is provided in Section 3 below (along with our simulation strategy). The contribution of this paper is three-fold. First, we follow Grepparud and Rasmussen (2004) in targeting the efficiency improvement at an individual production sector, the Scottish commercial Transport sector. Second, the impact of the 'disinvestment effect' (Turner, 2009) in local energy supply sectors in response to an energy efficiency improvement aimed at a single energy use sector, which mainly impacts on one local energy supply sector. Third, we explore the impacts on rebound and disinvestment effects of raising key parameters in the determination of the general equilibrium price elasticity of demand above unity, which, as we explain in our theoretical discussion in Section 2 below, is source of backfire effects (the extreme case of rebound, where net energy consumption actually increases in response to an efficiency improvement). This issue is explored in sensitivity analyses in several of the papers cited above, most notably Turner (2008), who carries out a systematic analysis of the price responsiveness in all production and trade parameters required to induce rebound and backfire effects. Here, we focus our analysis on individual parameters in the production function of a single sector targeted with an energy efficiency improvement, the Scottish commercial transport sector, and on rebound effects for the particular fuel type, refined oil, that is most heavily used in this sector. ${ }^{2}$ We present our simulation results and sensitivity analysis in Section 4. Section 5 provides a summary and conclusions.

\footnotetext{
${ }^{2}$ When we refer to 'oil' as an input to production in this paper, we refer to the refined oil that is the output of the Scottish 'Oil Refining and Distribution of Oil and Nuclear' sector - sector 22 in Appendix 1. This sector uses as an input the crude oil produced by the Scottish 'Oil and Gas Extraction' sector - sector 6 in Appendix 1 - and imported crude oil. Historically, the price of Scottish refined oil has been variable in response to contractions in supply in Scottish oil refineries.
} 


\section{Theoretical background}

\subsection{Defining the rebound effect}

Following Hanley et al (2009) and Turner (2008), we begin by distinguishing between energy measured in natural or physical units, E, and efficiency units, $\varepsilon$ (i.e. the effective energy service delivered). If we have energy augmenting technical progress at a rate $\rho$, the relationship between the proportionate change in $\mathrm{E}$ and $\varepsilon$ is given as:

$$
\dot{\varepsilon}=\rho+\dot{\mathrm{E}}
$$

This means that a given increase in energy efficiency has an identical impact to the same increase in physical energy inputs without the efficiency gain.

A given increase in energy efficiency generates an identical decrease in the price of energy in efficiency units (or the effective price of energy):

$$
\dot{p}_{\varepsilon}=\dot{p}_{E}-\rho
$$

Where $\dot{p}$ is the proportionate change in the price of energy in either natural or efficiency units.

In turn, if we hold the price of physical energy units constant, a reduction in the price of energy efficiency units should lead to an increase in demand for energy in efficiency units (assuming that the general equilibrium price elasticity of demand is not perfectly inelastic). This gives us the trigger for the rebound effect:

$$
\dot{\varepsilon}=-\eta \dot{p}_{\varepsilon}
$$

Where $\eta$ is the general equilibrium price elasticity of demand for energy and this has a positive sign.

The change in energy demand in natural units caused by the change in price is derived by substituting equation (2) and (3) into (1):

$$
\dot{E}=(\eta-1) \rho
$$


The rebound effect is calculated for a given increase in energy efficiency in all sectors of the economy as follows:

$$
R=\left[1+\frac{\dot{E}}{\rho}\right] \times 100
$$

Where $R$ is the rebound effect expressed in percentage terms. If only a subset of energy uses are targeted with the efficiency improvement, (5) is adjusted as follows:

$$
R=\left[1+\frac{\dot{E}}{\alpha \rho}\right] \times 100
$$

In the empirical work reported here energy efficiency is only improved in a subset of its uses: use by one production sector, commercial Transport services, and only locally supplied energy (not imports) is affected by the efficiency improvement (see Section 3.3). Therefore, in the numerator of (5b), we will confine our attention total use (in Scotland) of locally supplied energy and the parameter $\alpha$ in the denominator will be the share of this total affected by the efficiency improvement. In the simulations reported in Section 4 below, this will be the share of locally supplied energy consumption in Scotland that takes place in the commercial Transport sector.

If we substitute equation (4) into equation (5), the link between the rebound effect and the general equilibrium price elasticity of demand for energy is made explicit:

$$
R=\eta \times 100
$$

There are four important points and ranges of general equilibrium price elasticity and rebound values. These are summarised in Table 1.

\subsection{Empirical considerations and the implications for theoretical analysis of rebound effects}

In practice, however, there are two main issues that complicate consideration of potential rebound effects. First, the simple theoretical exposition above assumes that physical energy prices are held constant. This conceptual approach would be appropriate for a fuel that is imported and where the natural price is exogenous or only changes in line with the demand measured in natural units. However, as is the case in our target economy of Scotland, where energy is produced domestically 
(with energy as one of its inputs) the price of energy in physical units will be endogenous, giving further impetus for rebound effects.

Table 1. Key values of the general equilibrium price elasticity of demand for energy and rebound effects

\begin{tabular}{|c|c|l|}
$\begin{array}{c}\text { General } \\
\text { equilibrium price } \\
\text { elasticity }\end{array}$ & Rebound effect & Implication for energy efficiency improvement \\
\hline $\begin{array}{c}\text { (perfectly inelastic) } \\
0 \text { to } 1 \\
\text { (relatively inelastic) }\end{array}$ & $0 \%$ & $\begin{array}{l}\text { All of the energy efficiency improvement is reflected in a fall in } \\
\text { the demand for natural energy units. }\end{array}$ \\
\hline 1 (unitary elasticity) & $100 \%$ & $\begin{array}{l}\text { Some of the energy efficiency improvement is reflected in a fall } \\
\text { in the demand for natural energy units, but there is a degree of } \\
\text { rebound effect. }\end{array}$ \\
\hline$>1$ & $\begin{array}{l}\text { The reduction in energy demand from the efficiency } \\
\text { improvement is entirely offset by increased demand for energy as } \\
\text { prices fall. }\end{array}$ \\
\hline (elastic) & $\begin{array}{l}\text { The energy efficiency improvement leads to an increase in the } \\
\text { demand for energy in natural units that outweigh the reduction in } \\
\text { demand from the efficiency improvement. Such a phenomenon is } \\
\text { labelled as a 'backfire effect'. }\end{array}$ \\
\hline
\end{tabular}

The second issue is the problem of identifying of the general equilibrium elasticity of demand for energy, $\eta$. This is shown in the theoretical exposition above to be the crucial determinant of the size of rebound effects in response to a given change in energy augmenting technological progress. The responsiveness of energy demand at the aggregate level to changes in (effective and actual) energy prices will depend on a number of key parameters and other characteristics in the economy, as the theoretical analysis provided by Allan et al (2008b) demonstrates. As well as elasticities of substitution in production, which tend to receive most attention in the literature (see Saunders, 1992; and Broadstock et al, 2007, for a review), important parameters and characteristics are likely to include: price elasticities of demand for individual commodities; the degree of openness and extent of trade (particularly where energy itself is traded and energy efficiency improves in the energy supply sectors themselves - see Hanley et al, 2009); the elasticity of supply of other inputs/factors; the energy intensity of different activities; and income elasticities of energy demand (the responsiveness of energy demand to changes in household incomes). Thus, the extent of rebound effects is, in practice, always an empirical issue. 
Moreover, the analysis of potential rebound effects requires a general equilibrium framework due to the type and range of underlying effects that drive rebound. Turner (2008, p25) details these as follows:

(i) The pure engineering or efficiency effect resulting from the need to use less physical energy inputs to produce any given level of output;

(ii) The substitution effect resulting from the incentive to use more energy inputs as the price of these inputs falls relative to other input prices;

(iii) The composition effect in output choice at the aggregate level as relatively energy-intensive products benefit more from this fall in the effective price;

(iv) The output/competitiveness effect resulting from the fall in supply price of commodities that (directly and/or indirectly) use energy as an input to production;

(v) The income effect resulting from increased real household incomes, which will impact on household consumption of all commodities, including the direct and/or indirect consumption of energy.

\subsection{The disinvestment effect}

However, Turner $(2008,2009)$ demonstrates that general equilibrium analyses of the economy-wide response to increased energy efficiency and falling actual energy prices (where there is domestic supply of energy) also allow us to consider another potential effect, but this time one that will act to counter effects (ii) to (v) above and dampen long-run rebound effects. This is what Turner (2008, 2009) refers to as

(vi) The disinvestment effect, which may occur in domestic energy supply sectors if direct and derived demands for energy are not sufficiently elastic to prevent falling energy prices leading to a decline in revenue, profitability and the return on capital in these sectors.

Turner's $(2008,2009)$ disinvestment effect (previously observed but not explored in Allan et al's, 2007, UK analysis) counters the argument put forward by Wei (2007) and Saunders (2008) that rebound effects will always be bigger in the long run than in the short run. Wei and Saunders argue that because capital (and labour) are fixed in the short-run, the short-run rebound effect is also constrained. Thereafter, investment will occur (in response to increased marginal productivity of all factors as efficiency improves), allowing the space of production possibilities to expand as the economy adjusts to a long-run equilibrium, and rebound effects to grow. However, this prediction does not hold in Allan et al's (2007) UK analysis or Turner's $(2008,2009)$ analysis for Scotland and the UK in a number of cases. Where decreases in actual local energy prices trigger a decline in 
revenues to the local energy supply sectors this causes a sufficient drop in capital rental rates to stimulate disinvestment (a contraction in capacity) in these sectors. Such a decline in revenues will occur where the general equilibrium price elasticity of demand for energy is inelastic so that the increase in quantity demanded is less than proportionate to the drop in price. Just as positive investment allows the rebound effect to grow, this contraction in capacity in the energy supply sectors acts to constrain the long-run rebound effect.

In the empirical analysis reported in the current paper, while disinvestment does occur in response to increased energy efficiency in the Scottish commercial Transport sector, particularly in the Scottish (refined) oil supply sector ${ }^{3}$, and does dampen rebound effects over time, this is not sufficient to cause rebound effects to be smaller in the long-run than in the short-run. Nonetheless, as the discussion in Section 4 demonstrates, consideration of the disinvestment effect is important in explaining rebound values that appear very similar in the short- and long-run. This highlights the role of empirical general equilibrium analysis in elucidating the complex economy-wide interactions that underlie rebound effects and the contribution that such analyses can make in developing the theoretical literature. For example, the crucial distinction between the AMOSENVI empirical general equilibrium framework employed by Allan et al (2007) and Turner $(2008,2009)$ and the theoretical one presented by Wei (2007), which gives rise to the argument of a universal increase in capacity (and rebound effects that are always bigger in the long run than in the short run), is that Wei's model assumes that the return on capital is fixed at unity, whereas in AMOSENVI it is endogenously determined and affected by changing profitability. While Wei's (2007) theoretical analysis makes a number of simplifying assumptions, Turner's $(2008,2009)$ analysis of the disinvestment effect, as well as that in the current paper, highlights the potential ramifications of this single constraining assumption.

\section{Modelling strategy}

\subsection{AMOSENVI: An energy-economy-environment model of Scotland}

In this paper we use AMOSENVI, a computable general equilibrium (CGE) model parameterised on a Scottish SAM for 1999 (the most recent year for which appropriate physical energy use data have been used to extend the Scottish input-output tables - Scottish Executive, 2002, Turner, 2003). The AMOSENVI modelling framework, including the range of possible model configurations and the underlying database, is detailed in Hanley et al (2009). Here we provide an overview of the main model features. The main assumptions incorporated in the model configuration used here are listed in Table 2 below. However, two key elements of the model specification are particularly important in terms of the results presented in Section 4 of this paper. 
Table 2. AMOSENVI modelling assumptions

\begin{tabular}{|c|c|}
\hline Variable & Assumption \\
\hline Domestic transactors & Three groups: the personal/household sector; corporations; and government \\
\hline Commodities / activities & $\begin{array}{l}25 \text { in total (see Appendix 1), five of which are energy commodities / supplies and } \\
\text { one of which is commercial 'Transport" }\end{array}$ \\
\hline External transactors & $\begin{array}{l}\text { Two exogenous external transactors: the Rest of the UK (RUK) and the Rest of } \\
\text { the World (ROW), with demand for exports and imports sensitive to changes in } \\
\text { relative prices between (endogenous) domestic and (exogenous) external prices } \\
\text { (Armington, 1969). }\end{array}$ \\
\hline Final demand & $\begin{array}{l}\text { Four components: consumption; investment; government expenditure; and } \\
\text { imports }\end{array}$ \\
\hline Labour market & $\begin{array}{l}\text { A single Scottish labour market with perfect sectoral mobility and a bargained } \\
\text { real wage closure }\end{array}$ \\
\hline Production costs & Cost-minimisation in production regardless of the choice of other values \\
\hline Capital stock & $\begin{array}{l}\text { Updated between time periods to ensure that investment equals depreciation plus } \\
\text { some fraction of the gap between the desired and actual capital stock }\end{array}$ \\
\hline Migration & $\begin{array}{l}\text { Endogenous, with the population update between time periods related to the real } \\
\text { wage differential and the unemployment rate differential between Scotland and } \\
\text { RUK }^{6}\end{array}$ \\
\hline Production structure & $\begin{array}{l}\text { As summarised in Figure } 1 \text { below. The separation of different types of energy } \\
\text { and non-energy intermediate inputs is in line with the 'KLEM' (capital-labour- } \\
\text { energy-materials) approach commonly adopted in energy/environmental CGE } \\
\text { models }\end{array}$ \\
\hline Governm & the current application \\
\hline
\end{tabular}

First, our treatment of investment is particularly important in the context of the disinvestment effect. Within each period of the multi-period simulations using the AMOSENVI framework, both the total capital stock and its sectoral composition are fixed, and commodity markets clear continuously. Each sector's capital stock is updated between periods via a simple capital stock adjustment procedure, according to which investment equals depreciation plus some fraction of the gap between the desired

\footnotetext{
${ }^{3}$ See Footnote 2.

${ }^{4}$ The 25 production sectors are an aggregate of the Scottish Government's I-O framework (Scottish Executive, 2002, in the current model), which divides production across 128 sectors in accordance with the UK Standard Industry Classification (SIC).

5 A bargained real wage closure means that the regional consumption wage is directly related to workers' bargaining power and inversely related to the regional unemployment rate (Blanchflower and Oswald, 1994, Minford et al, 1994, Layard et al, 1991). This structure implies that local wages are flexible in that they respond to the local excess demand for labour. See Hanley et al (2009) for details.

${ }^{6}$ This treatment of migration is based on that of Harris and Todaro (1970). See Hanley et al (2009) for details.
} 
and actual capital stock. The desired capital stock is determined on cost-minimisation criteria and the actual stock reflects last period's stock, adjusted for depreciation and gross investment. The economy is assumed initially to be in long-run equilibrium, where desired and actual capital stocks are equal.

This treatment is wholly consistent with sectoral investment being determined by the relationship between the capital rental rate and the user cost of capital. The capital rental rate, or return on capital, is the rental that would have to be paid in a competitive market for the (sector specific) physical capital while the user cost is the total cost to the firm of employing a unit of capital. Given that we take the interest, capital depreciation and tax rates to be exogenous, the capital price index is the only endogenous component of the user cost. If the rental rate exceeds the user cost, desired capital stock is greater than the actual capital stock and there is therefore an incentive to increase capital stock. The resultant capital accumulation puts downward pressure on rental rates and so tends to restore equilibrium. In the long-run, the capital rental rate equals the user cost in each sector, and the riskadjusted rate of return is equalised between sectors. We assume that interest rates are fixed in international capital markets, so that the user cost of capital varies with the price of capital goods.

The key point to note at this point (and what drives the disinvestment effect observed in the case of the domestic oil supply sector in the simulations reported in Sections 4) is that the reverse argument will also hold. If output prices in any sector $i$, e.g. the Scottish (refined) Oil sector (sector 22 in the sector listing in Appendix 1; hereafter referred to as the Oil sector) fall and the increase in demand for that sector's output do not rise sufficiently to prevent total revenue, and therefore profitability, from falling (i.e. if the general equilibrium demand for Oil sector output is not sufficiently responsive, or elastic, to the drop in price), the return on capital in this sector will decrease. If the return on capital (capital rental rate) drops so that it is less than the user cost, desired capital stock will be less than actual capital stock in the Oil sector, providing an incentive to reduce capital stock in that sector. The resultant shedding of capital will put upward pressure on the capital rental rate (and output price) in the Oil sector in order to restore equilibrium. In the long-run the capital rental rate will again be equal to the user cost in the Oil sector, but with a reduced level of capital stock and production capacity.

The second important element of model specification for the application presented here is our treatment of energy and other inputs to production. This is important in terms of how we introduce the energy efficiency improvement and input substitution possibilities in response to this shock. The nested production structure applied to each of the 25 production sectors is illustrated in Figure 1. This separation of different types of energy and non-energy inputs in the intermediates block is in line with the general 'KLEM' (capital-labour-energy-materials) approach that is most commonly adopted in the literature. There is currently no consensus on precisely where in the production structure energy should be introduced, for example, within the primary inputs nest, most commonly combining with 
capital (e.g. Bergman, 1988, 1990), or within the intermediates nest (e.g. Beauséjour et al, 1995), but there has been an ongoing debate over a number of years in the CGE literature in this regard (see Turner, 2008, 2009). Given that energy is a produced input, it seems most natural to position it with the other intermediates, and, for simplicity, this is the approach we adopt here. However, any particular placing of the energy input in a nested production function restricts the nature of the substitution possibilities between other inputs. The empirical importance of this choice is an issue that requires more detailed research, which are currently engaged in (for the $\mathrm{UK}^{7}$ ) as part of the ESRCfunded programme of research of which this paper is part, building on the econometric approach adopted by Kemfert (1998).

In the AMOSENVI model used here, the multi-level production functions in Figure 1 are generally of constant elasticity of substitution (CES) form, so there is input substitution in response to relative price changes, but with Leontief and Cobb-Douglas (CD) available as special cases. In the simulations reported here, Leontief functions are specified at two levels of the hierarchy in each sector - the production of the non-oil composite and the non-energy composite - because of the presence of zeros in the base year data on some inputs within these composites. CES functions are specified at all other levels.

At present, econometric estimates of key parameter values are not available for the Scottish model. ${ }^{8}$ In the base case scenario simulations reported in Section 4, the default AMOSENVI model configuration as explained in Hanley et al (2009) and Turner (2008) is imposed. In summary, this means that we generally assume elastic export and import direct and derived energy demands (i.e. for an X\% change in relative prices, demand will change by more than $\mathrm{X} \%$ ) but inelastic local intermediate demands (i.e. for an $\mathrm{X} \%$ change in relative prices, demand will change by less than $\mathrm{X} \%)$. More specifically, the elasticity of substitution at all points in the multi-level production function is assumed to take the value of 0.3, apart from where Leontief functions have been imposed and in the case of the electricity composite, where a higher value of 5.0 is imposed (to reflect the homogeneity of electricity from different sources and consequent higher degree of substitutability). The Armington trade elasticities are generally set at 2.0, with the exception of exports of renewable and non-renewable electricity, which are set at 5.0, again to reflect the homogeneity of electricity as a commodity in use. However, it is important to note that these are all likely to be key parameters in determining rebound effects. Turner $(2008,2009)$ shows that as price responsiveness increases in any part of the system, rebound effects will also increase. This is demonstrated here in the case of the commercial Transport sector.

\footnotetext{
${ }^{7}$ At present, appropriate data for econometrically estimating many key parameters, such as elasticities of substitution in the KLEM production function, are not available at the Scottish (regional) level. Our current research in this area is focused at the UK (national) level.
} 


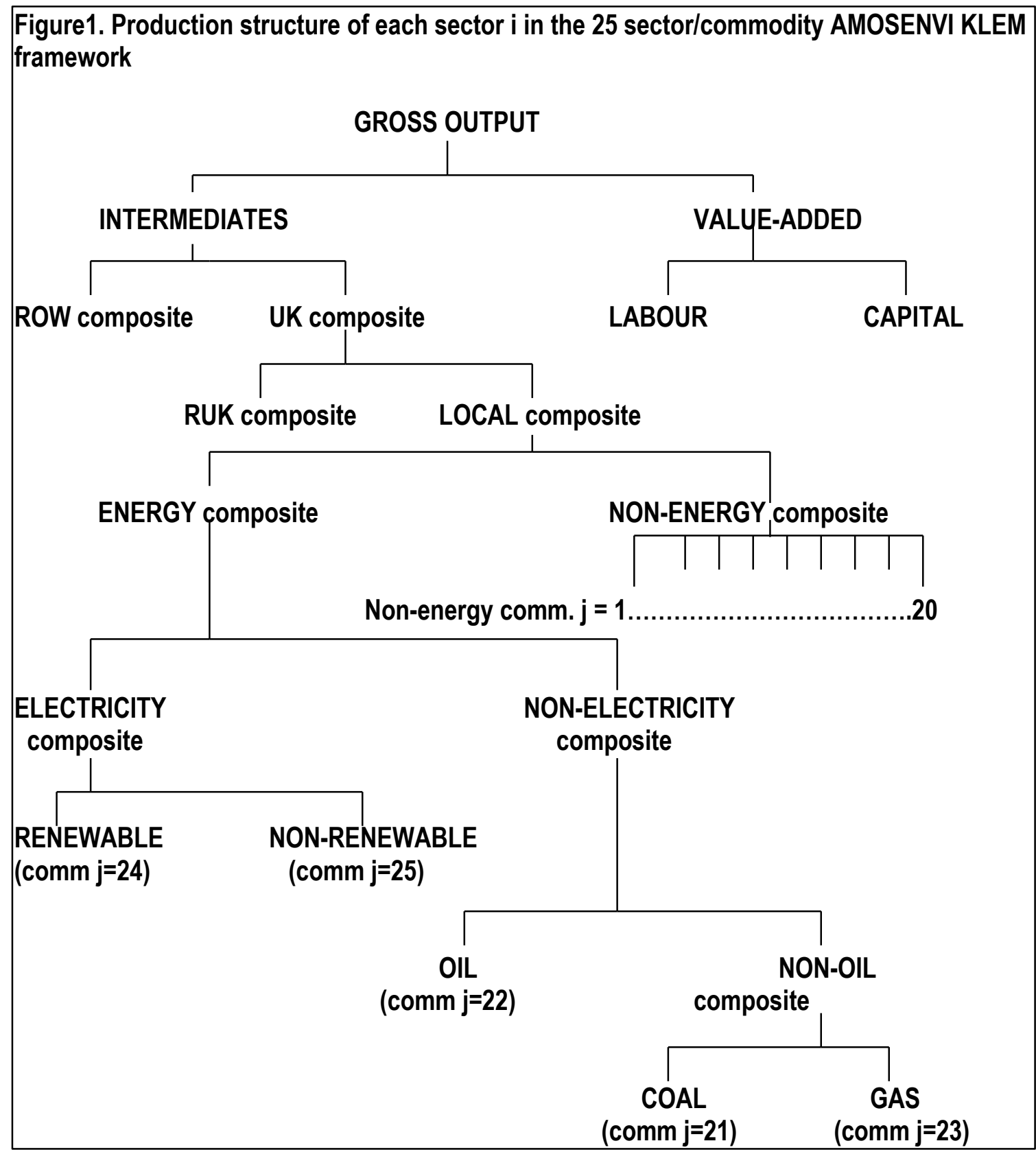

3.2 Modelling rebound effects from increased energy efficiency in the Scottish commercial Transport sector

As noted in Section 1, to date Grepparud and Rasmussen (2004) is the only empirical general equilibrium rebound study to examine in any detail the economy-wide impacts of energy efficiency improvements that take place in individual production sectors, including transport. The most commonly studied area in the wider rebound literature is personal transport by private car (Sorrel, 2007). Furthermore, previous studies tend to focus on the direct rebound effect only. General equilibrium analysis of increased energy efficiency in personal/household transport would be a

\footnotetext{
${ }^{8}$ See Footnote 7
} 
valuable area of research. However, the AMOSENVI model is not yet specified to do so. Instead we confine our attention to the impacts of increased energy efficiency in the in production rather than final consumption activities. In particular, we focus on general equilibrium impacts of increased energy efficiency in just one of the 25 production sectors in AMOSENVI, the commercial Transport sector, which adopts selected elements of the SIC 'Transport, Storage and Communication' sector, as detailed in Table 3. That is, we look specifically at the economic impact of an energy efficiency gain in industries that supply transport as a commercial service and not private demand for transport, such as use of a private car.

Table 3. Sub-sectors within the Scottish 'Transport' sector

\section{\begin{tabular}{l|l|l|l} 
Industry $/$ Product & Description
\end{tabular}}

Group Number (IOC

classification)

\begin{tabular}{|c|l|c|}
\hline 93 & Transport and railways & 60.1 \\
\hline 94 & Other land transport; & 60.2 \\
& transport via pipelines & 60.3 \\
\hline 95 & Water transport & 61 \\
\hline 96 & Air transport & 62 \\
\hline 97 & Supporting and auxiliary transport activities; & 63 \\
& activities of travel agencies & \\
\hline
\end{tabular}

In the 1999 Scottish input-output tables (Scottish Executive, 2002), which form the core of the SAM database for Scotland on which the AMOSENVI model used here is calibrated, the Scottish Transport sector directly accounts for $6.2 \%$ of Scottish output, 5.2\% of GDP and $4.1 \%$ of (full-time equivalent) employment. In terms of energy use, it is the most intensive and heaviest overall user of oil out of the 25 sectors identified in the model.

As stated above, the only CGE modelling study on the impacts of energy-efficiency that concentrates on specific sectors is that conducted by Grepperud and Rasmussen (2004). As part of this study, they introduce a transport-oil efficiency improvement into the 'Road Transport' ${ }^{9}$ sector and find only a small degree of rebound. This is predominantly explained as a result of the fact that "substitution possibilities between factors are very small.” (Grepperud and Rasmussen, 2004, p277)

\footnotetext{
${ }^{9}$ Although it is not explicitly specified in the paper, it is strongly inferred that 'Road Transport' in this instance refers to commercial transport, e.g. freight, as opposed to private transport.
} 
In terms of non-CGE studies, Graham and Glaister (2002) conduct an extensive review of the international literature on road traffic and fuel demand in order to identify the magnitude of relevant elasticities. In doing so, they look at freight traffic elasticities and, despite conceding that there is a wide variation in the published estimates, they find that $42 \%$ of these estimates fall within the range of -0.4 and -0.8 . This is equivalent to a partial equilibrium rebound effect of $40-80 \%$. Gately (1990) uses econometric analysis on US data to estimate the fuel price elasticity of HGV transport. He finds a statistically significant value of -0.37 , equivalent to a rebound effect of $37 \%$. However, it is important to bear in mind that these estimates are not of general equilibrium elasticities and, therefore, will not equate to full system-wide rebound estimates.

\subsection{Simulation strategy and calculation of rebound effects for (refined) oil}

We introduce the energy efficiency shock by increasing the productivity of the energy composite in the production structure of the Transport sector (see Figure 1). This procedure operates exactly as in equation (1). It is a one-off exogenous (and costless ${ }^{10}$ ) permanent step increase in energy augmenting technological progress (i.e. increasing units of output produced per physical unit of energy input). Note that under the current production structure in Figure 1, we are only able to apply the efficiency shock to use of local energy, and not imports. This is an important limitation (see Turner, 2008) and one that we aim to address in future research.

Given this limitation, in calculating rebound effects using equation (5b) from Section 2.2, it is appropriate to only consider total energy use in terms of the use (in Scotland) of locally supplied energy in the numerator of equation (5b) (since imports of energy will change in proportion with other imported commodities at a higher level of the production function in Figure 1 above, rather in response to actual energy demands). In terms of the denominator of equation (5b), we need to weight the energy efficiency gain in the Transport sector by the proportion of total use (in Scotland) of locally supplied energy accounted for by the Transport sector in the base case. In our 1999 data base intermediate input demand from the Transport sector accounts for $1.5 \%$ of total demand for Scottish electricity consumed in Scotland, with the equivalent figures for non-electricity energy (coal, oil and gas combined) and for oil alone being 5.3\% and 15.2\% respectively. These numbers give us the $\alpha$ parameter in the denominator in equation $(5 b)$ in calculating the economy wide rebound effect (for the Transport sector specific rebound effect, the denominator will be $5 \%$ as all sectoral level use of local

\footnotetext{
${ }^{10}$ Introducing consideration of costs involved in introducing an energy efficiency improvement will affect the nature and size of rebound effects (see Allan et al, 2007), as will the precise nature of its introduction. Such issues will be considered in future research under the ESRC-funded programme of research of which this paper. Here, in the first instance, the analysis is simplified by focussing on an exogenous and costless increase in energy efficiency. This is an important step as it allows us to consider the main basic drivers of the rebound
} 
energy is targeted with the shock). In terms of the size of the efficiency shock, $\rho$, in this experimental analysis we set this somewhat arbitrarily at $5 \%$ (but do conduct sensitivity analysis of the size of the rebound effect to the size of the shock).

We also focus specifically on the (refined) Oil rebound effect (referred to hereafter simply as the Oil rebound effect $^{11}$ ), given that this is the main type of energy consumed by the Transport sector. However, because we are not able to implement the efficiency improvement at the commodity level in the current format of AMOSENVI, we model an increase in all energy efficiency, and then calculate equation 5(b) for oil consumption. This means that the oil rebound effect as measured here is a response to a general energy efficiency increase, and that the impacts identified will reflect this increase in efficiency of all energy types. However, it is important to bear in mind that aggregate (refined) oil use may also increase as an indirect result of the increased efficiency in other fuel types.

Given that an increase in energy efficiency in the Transport sector is a relatively small (but positive) supply-side shock, the impacts on key macroeconomic variables are limited and we do not focus heavily on these in reporting our results. Instead, we focus on the impacts on (refined) oil consumption and rebound effects, on the disinvestment effect (as reflected in falling capital rental rates and capital stocks in the Scottish Oil supply sector ${ }^{12}$ ), and on the sensitivity of these results to key parameter specifications. We refer to both short and long run equilibria, where these refer to population and capital stocks being either fixed (in the first period after the shock is introduced) or fully adjusted respectively. We also refer to the period-by-period (year-by-year) adjustment of key variables. All results are reported in terms of percentage changes from the base values given by the 1999 Scottish SAM. The CGE framework assumes that the baseline data represents a long-run economic equilibrium, so if the model is run forward without any shock this original equilibrium is replicated in each period. Thus the percentage changes against these values in each period are entirely attributable to the simulated increase in energy efficiency.

\section{Simulation results}

\subsection{Base case scenario (default model configuration)}

The increase in energy efficiency is a positive supply shock targeted specifically on the Transport sector. As our model assumes a bargained real wage closure, a priori we might predict that such a shock will lower prices, improve competitiveness, increase employment and stimulate output. Table 4,

effect (i.e. the general equilibrium responses to reductions in effective, and actual, energy prices) and the disinvestment effect in isolation.

${ }^{11}$ See Footnote 2. 
which shows a summary of the short and long run impact on key macroeconomic variables confirms that these high level predictions are accurate. However, in contrast to results reported in Hanley et al (2009) and Turner (2008), where all sectors of the Scottish economy are targeted with the energy efficiency improvement, the positive impact on macroeconomic variables is relatively small.

Table 4. The Aggregate Impact of a 5\% Increase in Energy Efficiency in the Scottish commercial Transport Sector (Percentage changes from base year equilibrium)

\begin{tabular}{|l|c|c|}
\hline & Short-run & Long-run \\
\hline GDP (income measure) & 0.004 & 0.022 \\
Consumption & 0.008 & 0.021 \\
Investment & 0.008 & 0.020 \\
Exports & 0.013 & 0.027 \\
Imports & 0.003 & 0.005 \\
& & \\
Nominal before-tax wage & 0.007 & -0.004 \\
Real T-H consumption wage & 0.004 & 0.000 \\
Consumer price index & 0.003 & -0.004 \\
& & \\
Total employment (000's): & 0.005 & 0.021 \\
Unemployment rate (\%) & -0.039 & 0.000 \\
Total population (000's) & 0.000 & 0.021 \\
& & -3.086 \\
Transport oil consumption (tonnes) & -3.174 & -0.462 \\
Total oil consumption (tonnes) & -0.483 & 38.3 \\
Transport oil rebound effect (\%) & & 39.2 \\
\hline Total oil rebound effect (\%) & 36.5 & \\
\hline
\end{tabular}

The net effect on imports depends upon the relative strength of the price effect and the boost in economic activity. In this instance, total imports rise as the income effect of increased Scottish demand dominates the competitiveness effect of the relative decrease in domestic prices. However, the fall in the relative price of Scottish goods also causes exports to rise, and in this instance by a greater amount than the increase in imports, meaning that Scotland's trade balance improves.

Whilst the real take-home consumption wage increases and the unemployment rate decreases in the short-run, in the longer run we observe that real wages and the unemployment rate return to their original baseline equilibrium as in-migration leads to a higher population level and labour supply. The higher total employment, coupled with an increase in the overall capital stock, ensures that the

\footnotetext{
${ }^{12}$ Sector 22 in Appendix 1.
} 
new equilibrium output level is higher than in the baseline. Scottish output prices fall over the long run, as reflected in the CPI with consequent positive competitiveness effects across the board.

The targeted increase in energy efficiency, and consequently the cost of production, means that the price of output declines most dramatically in the transport sector in all time periods. This lower price has the knock on impact of increasing actual output from the sector, by as much as $0.20 \%$ in the long run

Despite the 5\% increase in energy efficiency, 'Transport' (refined ${ }^{13}$ ) oil consumption only falls by $3.2 \%$ in the short run and by slightly less, $3.1 \%$ over the long run. This dictates that the 'Transport' oil rebound effect is $36.5 \%$ in the short run and $38.3 \%$ in the long run. This is largely driven by the efficiency gains made within the sector prompting an increase in output, as highlighted in the previous paragraph, and a shift to more energy-intensive production.

Figure 2. Impact of a 5\% energy efficiency improvement in the Scottish Transport secotr on output prices in Scottish energy supply sectors (\% change from base)

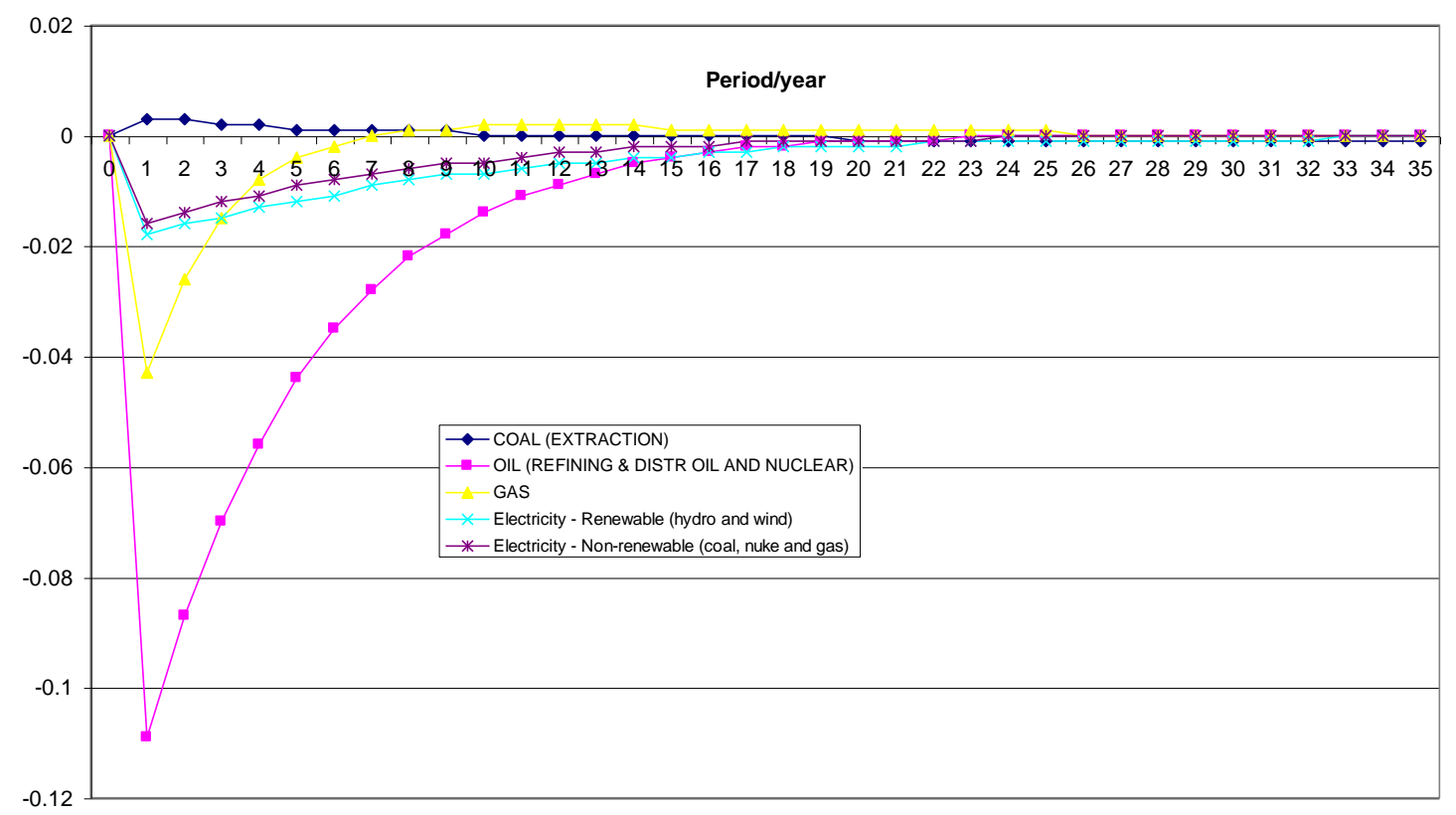

However, there are more complex interactions at the economy-wide level. The total (refined) oil rebound effect is $36.4 \%$ in the short-run, rising to $39.2 \%$ in the long-run, but this underlies a proportionately smaller drop in energy consumption at the economy-wide level. Recall that Transport consumption of Scottish oil is just over 15\% of the total consumed in Scotland. Almost all of the change in (refined) oil consumption is due to decreased net consumption in the Transport sector (given that this is where the efficiency shock is targeted). The impacts of the shock are not entirely 
felt in the Transport sector, however. The main impact outside of this sector is on local energy prices, where both the effective and actual price fall, with the exception of coal, in response to the improvement in efficiency in all types of energy use in the Transport sector. The impact on actual local energy prices is shown in Figure 2.

The fall in actual energy prices does give further impetus to rebound effects in the economy. However, following the arguments of Wei (2007) and Saunders (2008), we would expect the drop in actual local energy prices to stimulate demand for the outputs of these sectors (as well as the positive impact on the Transport sector itself) and the efficiency improvement, though limited in this case, to expand production possibilities. We return to the latter momentarily. In terms of the expected demand stimulus, there is a positive demand response to falling output prices in the energy supply sectors (with small increases in export demands and household final consumption). However, the overall impact on the energy sectors (again with the exception of coal, which is not greatly affected by the efficiency improvement in Transport, which is a relatively light user of this type of energy) is a contraction in outputs, as shown in Figure 3.

Figure 3. Impact of a $5 \%$ increase in energy efficiencyc in the Scottish Transport sector on output in the Scottish energy supply sectors (\% change from base)

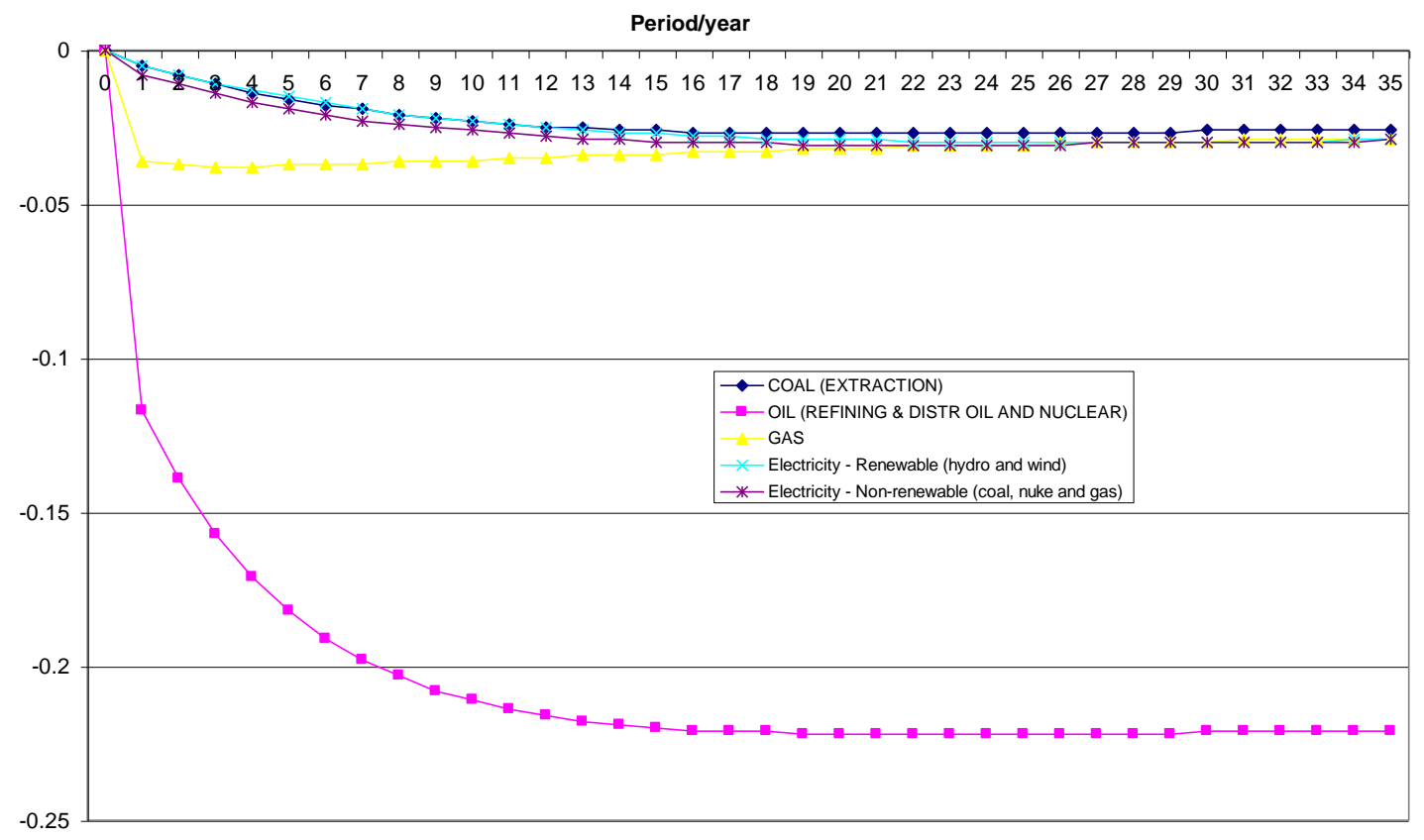

The Scottish energy supply sector that suffers most is the Scottish (refined) Oil supply sector. Output from the 'Oil' sector falls by $-0.12 \%$ in the short-run, and by $-0.22 \%$ in the long-run. The short-run effect occurs because the energy efficiency gain causes an initial reduction in the demand for local

\footnotetext{
${ }^{13}$ See Footnote 2.
} 
energy. However, the reduction in energy demand also causes the price of Scottish (refined) Oil prices to fall, by $-0.11 \%$ in the short-run, and we would expect this to stimulate demand, boosting output in this sector. However, while there is a positive demand stimulus as the price of Scottish refined Oil falls, including positive substitution and competitiveness effects within the targeted Transport sector itself (where we do see a positive oil rebound effect), the net effect is that Scottish Oil output continues to fall over time. The reason for this is that the simultaneous net declines in price and demand causes profitability in the Scottish energy sectors, but particularly the Oil supply sector (where the largest fall in price occurs) to fall such an extent that disinvestment occurs - i.e. firms begin to run down their capital stocks. This happens because the return on capital in what are relatively capital-intensive industries falls, triggering what Turner (2008) refers to as the disinvestment effect. Again, this is most apparent in the Scottish Oil sector. Capital rental rates (the return on capital) fall in the short run, triggering disinvestment and a contraction in capacity. In order to halt the disinvestment and reach a new equilibrium (with a lower capital stock) prices have to begin rising again to allow the return on capital to be restored at a rate equal to the user cost of capital. The process of adjustment in capital rental rates and the capital stock in the Scottish Oil supply sector is shown in Figure 4.

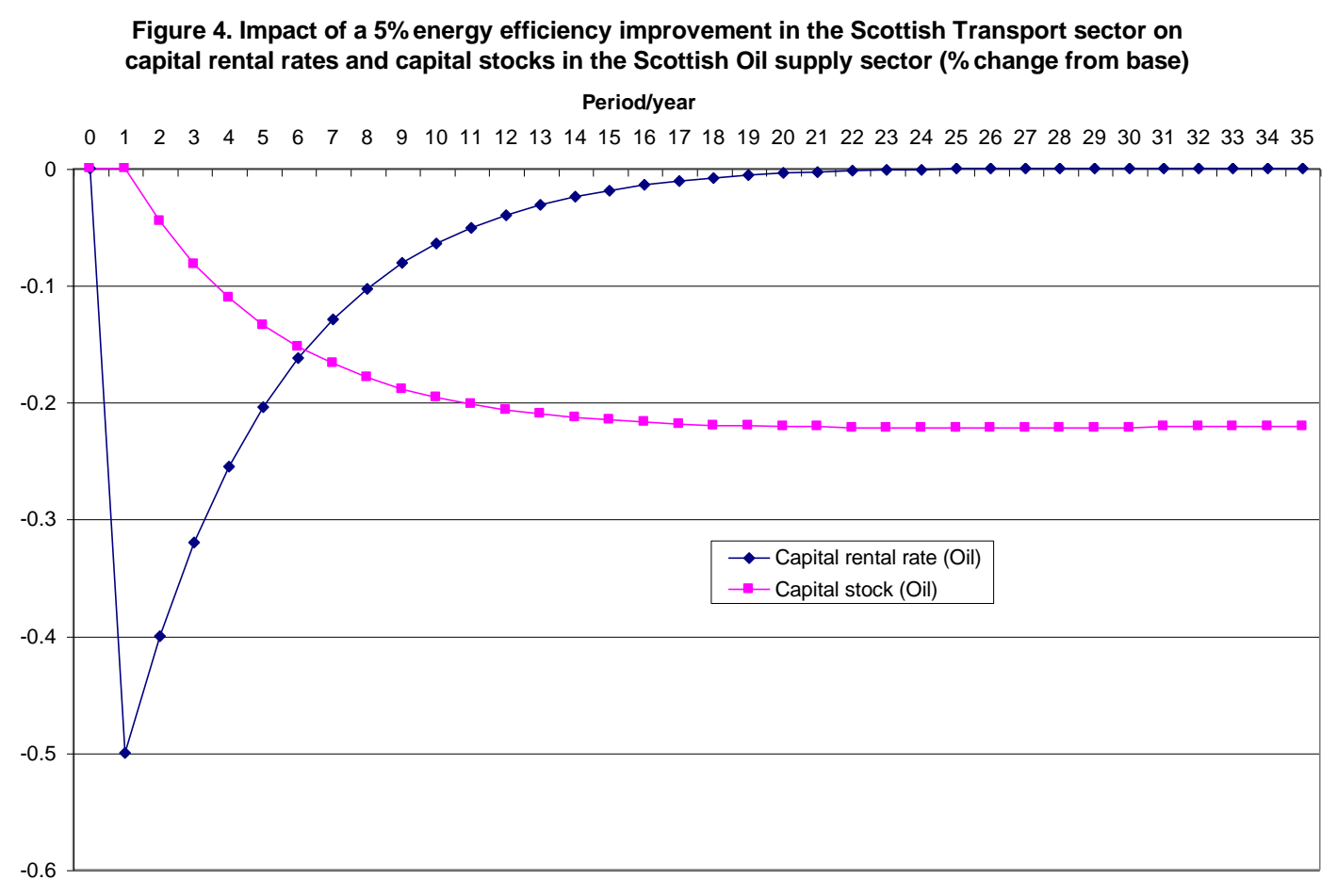

The arguments of Wei (2007) and Saunders (2008) that improved efficiency would be expected to expand production possibilities are correct in so far as there is an aggregate increase in investment at the economy-wide level (as shown in the results in Table 4). The biggest proportionate increase in 
capital stock and production possibilities is observed in the Transport sector, where the capital stock increases by $0.15 \%$ over the long run. However, in the case of the energy supply sectors, and particularly with respect to Scottish Oil, falling prices in the presence of insufficiently elastic demand trigger a disinvestment effect. The consequent rise in local energy prices as supply becomes more inelastic dampens the long-run rebound effect. As noted earlier, in Section 2, the disinvestment effect here is not sufficient to mean that the long run rebound effects are constrained to the extent of being smaller than those in the short-run (as found in a number of cases by Turner, 2008, 2009). Nonetheless, the disinvestment effect does constrain the long-run oil rebound effect reported in Table 4. The next question, then, given that the general equilibrium price elasticity of demand for energy is the key driver of both the rebound and disinvestment effects, is whether the results reported in this section are sensitive to variations in the specification of key parameter values that determine the price responsiveness of the system to the efficiency improvement.

\subsection{Sensitivity analysis}

Before we turn our attention to parametric sensitivity, given that the value of our 5\% efficiency shock has been somewhat arbitrarily determined, Table 5 shows the oil consumption and rebound effects if we rescale the shock to $1 \%$ and $10 \%$ respectively. The purpose of such sensitivity analysis is to identify whether the impact of an energy efficiency gain is approximately linear or whether any threshold effects exist, such as the rebound effect increasing in magnitude if the original energy efficiency shock is of a specific size. Such analysis has important policy implications, as the findings dictate whether energy efficiency improvements demonstrate increasing, constant or decreasing returns to scale against a specific environmental objective.

Table 5. Sensitivity of results (\% change from base year equilibrium) to size of energy efficiency improvement

\begin{tabular}{|l|cc|cc|c|c|}
\hline \multicolumn{1}{|c|}{ Size of efficiency improvement } & \multicolumn{3}{|c|}{$1 \%$} & \multicolumn{2}{c|}{$5 \%$ (base case) } & \multicolumn{1}{c|}{$10 \%$} \\
\hline & Short run & Long run & Short run & Long run & Short run & Long run \\
Transport oil consumption (tonnes) & -0.655 & -0.637 & -3.174 & -3.086 & -6.113 & -5.948 \\
Total oil consumption (tonnes) & -0.100 & -0.095 & -0.483 & -0.462 & -0.930 \\
& & & & & -0.890 \\
Transport oil rebound effect (\%) & 34.5 & 36.3 & 36.5 & 38.3 & 38.9 \\
Total oil rebound effect (\%) & 34.4 & 37.2 & 36.4 & 39.2 & 38.8 \\
\hline
\end{tabular}

While the size of the change in energy consumption is obviously sensitive to the size of the increase in efficiency, the results in Table 5 show that there is some quantitative difference and the impact of the efficiency gain does not seem to be linear. It is apparent that both the short- and long-run rebound effects increase as the original energy efficiency improvement does, suggesting that there are decreasing returns to scale to energy efficiency improvements. This implies that the general equilibrium price elasticity of demand becomes more elastic as the energy efficiency improvement 
becomes larger, a conclusion that is interesting, as it may seem to run contrary to general economic principles. ${ }^{14}$ This reinforces the value of taking a general equilibrium approach as opposed to a partial equilibrium one. Due to this field of research being relatively new, there is currently no other literature to refute or support this finding. However, as with the areas previously highlighted, this may also be an issue for future research to consider in more detail.

In terms of parametric sensitivity, on the other hand, existing studies do suggest that as we increase the values of key parameters, the size of rebound effects will increase. This is in line with theoretical predictions: in Section 2.1 we explained that if the general equilibrium price elasticity of demand for energy is greater than unity, we would expect to observe backfire effects (i.e. extreme rebound of over $100 \%$, where energy consumption actually increases in response to an energy efficiency improvement). This potential outcome will be of greatest concern to policymakers who may wish to employ energy efficiency improvements to reduce the level of $\mathrm{CO} 2$ emissions generated in the economy. However, in Section 2.2 we went on to argue that the identification of the general equilibrium price elasticity of demand is not straightforward. The responsiveness of energy demand at the aggregate level to changes in (effective and actual) energy prices will depend on a number of key parameters and other characteristics in the economy, such as elasticities of substitution in production; price elasticities of demand for individual commodities; the degree of openness and extent of trade (particularly where energy itself is traded); the elasticity of supply of other inputs/factors; the energy intensity of different activities; and income elasticities of energy demand. Turner $(2008,2009)$ shows that, in general, where elasticities of substitution in production are raised above unity, backfire effects occur, suggesting that these are indeed key parameters, as suggested by Saunder's (1992) early results and the recent review of Broadstock et al (2007). However, the previous economy-wide analyses for Scotland by Hanley et al (2009) and Turner (2008) suggest that export demand elasticities will be important in driving backfire effects where energy efficiency improvements are aimed at the energy supply sectors themselves, while Allan et al (2007) and Turner $(2008,2009)$ demonstrate that the same does not hold in the case of the UK (where trade in energy in more limited). In short, the nature of the general equilibrium price elasticity of demand will depend on the structure of the target economy and sector(s) that efficiency shocks are aimed at (i.e. it will be different for every economy, every sector and every shock and is actually given ex post by the value of the rebound effect, though the accuracy of this value will be determined by the accuracy of model specification).

In terms of the disinvestment effect, Turner's (2008) analysis for Scotland (where the efficiency improvement is targeted at all production sectors), suggests that this will disappear as export demand

\footnotetext{
${ }^{14}$ In making an efficiency gain, we are implicitly increasing disposable income and, therefore, are making the price of energy a smaller proportion of any given budget; traditionally we might expect such an action to reduce the price elasticity of demand. However, these results suggest that the opposite occurs.
} 
elasticities grow. However, even with production elasticities greater than unity, Turner (2008) still finds some disinvestment effects, though mainly in the electricity sectors, which dominate the Scottish and UK results when a general energy efficiency improvement is applied to all sectors.

Here, we repeat our simulations of a 5\% increase in energy efficiency aimed at the Transport sector and pick out a few parameters that may be important in the determination of the general equilibrium price elasticity of demand for this particular shock. First, since just over $40 \%$ of Transport output (in our base year of 1999) goes to meet export demand, we raise the value of the export demand elasticities for this sector from 2.0 in the default configuration to 4.0. This has a significant impact on the key macroeconomic indicators of GDP, and total Scottish household consumption and investment demand, increasing the long run growth in these variables by around $85 \%$. However, the third and fourth columns of Table 6 show that, without increasing the value of production parameters to make it easier to substitute in favour of energy, the (refined) oil consumption and rebound effects are not greatly different to what is observed in the base case scenario (shown again in the first and second columns).

Table 6. Sensitivity of results ( $\%$ change from base year equilibrium) to key parameter values

\begin{tabular}{|c|c|c|c|c|c|c|c|c|c|c|}
\hline \multirow[t]{2}{*}{ Scenario } & \multicolumn{2}{|c|}{$\begin{array}{c}\text { Base case (default } \\
\text { AMOSENVI } \\
\text { parameters) }\end{array}$} & \multicolumn{2}{|c|}{$\begin{array}{c}\text { Transport export } \\
\text { demand elasticities } \\
4.0 \\
\end{array}$} & \multicolumn{2}{|c|}{$\begin{array}{c}\text { Oil export demand } \\
\text { elasticities } \\
4.0 \\
\end{array}$} & \multicolumn{2}{|c|}{$\begin{array}{c}\text { Elasticity of } \\
\text { intermediates and } \\
\text { value-added } 1.0\end{array}$} & \multicolumn{2}{|c|}{$\begin{array}{l}\text { Elasticity of energy } \\
\text { and non-energy } \\
\text { intermediates } 1.0\end{array}$} \\
\hline & $\begin{array}{c}\text { Short run } \\
0.0040\end{array}$ & $\begin{array}{c}\text { Long run } \\
0.0220\end{array}$ & $\begin{array}{c}\text { Short run } \\
0.0060\end{array}$ & $\begin{array}{c}\text { Long run } \\
0.0410\end{array}$ & $\begin{array}{c}\text { Short run } \\
0.0040\end{array}$ & $\begin{array}{c}\text { Long run } \\
0.0220\end{array}$ & $\begin{array}{c}\text { Short run } \\
0.0020\end{array}$ & $\begin{array}{c}\text { Long run } \\
0.0180\end{array}$ & $\begin{array}{c}\text { Short run } \\
0.0030\end{array}$ & $\begin{array}{c}\text { Long run } \\
0.0190\end{array}$ \\
\hline Consumption & 0.0080 & 0.0210 & 0.0110 & 0.0390 & 0.0080 & 0.0210 & 0.0060 & 0.0170 & 0.0060 & 0.0180 \\
\hline Investment & 0.0080 & 0.0200 & 0.0110 & 0.0370 & 0.0090 & 0.0200 & 0.0080 & 0.0190 & 0.0070 & 0.0180 \\
\hline Transport oil consumption (tonnes) & -3.1743 & -3.0861 & -3.1422 & -2.9184 & -3.1744 & -3.0861 & -3.0393 & -3.0010 & 0.0728 & 0.1423 \\
\hline Total oil consumption (tonnes) & -0.4828 & -0.4617 & -0.4786 & -0.4262 & -0.4827 & -0.4617 & -0.4630 & -0.4493 & 0.0111 & 0.0350 \\
\hline Transport oil rebound effect (\%) & 36.51 & 38.28 & 37.16 & 41.63 & 36.51 & 38.28 & 39.21 & 39.98 & 101.46 & 102.85 \\
\hline Total oil rebound effect (\%) & 36.38 & 39.16 & 36.94 & 43.85 & 36.40 & 39.17 & 39.00 & 40.80 & 101.46 & 104.62 \\
\hline
\end{tabular}

In terms of the disinvestment effect, Figures 5 and 6 below show that increasing the price elasticity of export demand for Transport sector outputs has very little impact on what was observed in the base case scenario in terms of capital rental rates and capital stocks. In the fifth and sixth columns of Table 6 we vary the price elasticity of export demand parameters on Oil sector output rather than Transport sector output, but the results here and in Figures 5 and 6 demonstrate that even this increase in demand responsiveness as Oil sector prices fall does not halt the disinvestment effect, though it does slow down the adjustment process (with a smaller short-run drop in capital rental rates, but longer adjustment process of both the capital rental rate and capital stock). Moreover, in contrast to increasing the price responsiveness of export demand in the Tranport sector, this adjustment has only a negligible (positive) impact on short run aggregate investment and the total oil rebound effect; otherwise the macroeconomic results of changing this parameter are not sensitive to this change in specification. 
Turning our attention to production elasticities, next we test the sensitivity of our results if we raise the value of each of the two production elasticities that most directly affect the use of energy inputs in the KLEM production function from the default (inelastic) values of 0.3 to unity. First we change the change the value of the elasticity of substitution between value-added (the labour-capital, or KL, composite in Figure 1) and composite intermediate inputs in the Transport sector production function to 1 . The impacts on the oil rebound effect are shown in the seventh and eighth columns of Table 6 and the impacts on the capital rental rate and capital stocks in the Oil sector are shown in Figures 5 and 6.

Figure 5. Sensitivity of Oil sector capital rental rate results to key parameter values (\% change from base)

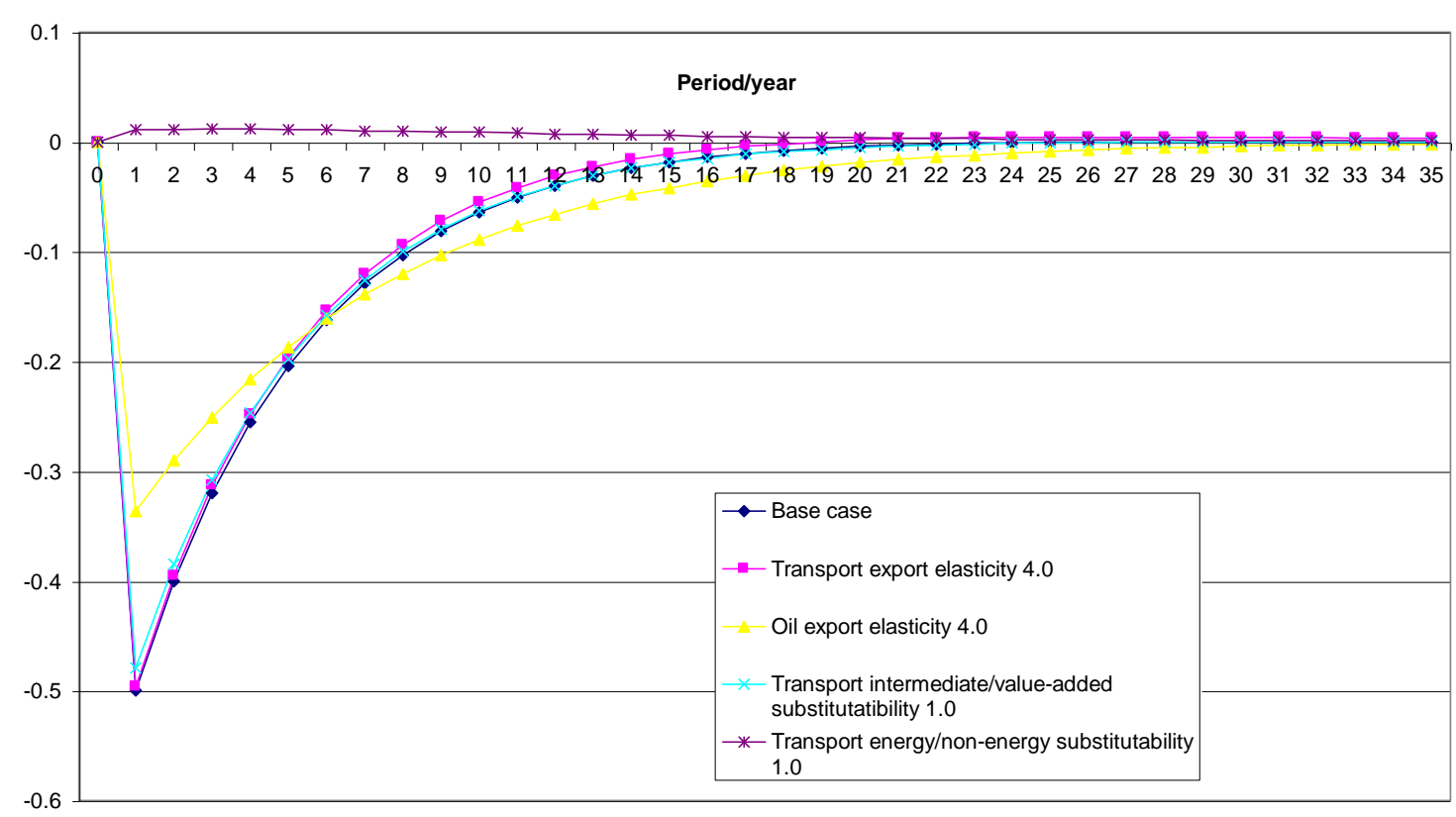

Table 6 and Figures 5 and 6 show that increasing substitutability between intermediates and valueadded to unity has very little quantitative and no qualitative impact on the oil rebound effect or the Scottish Oil sector disinvestments effect. Thus, like the export demand parameters, we can conclude that it does not have a great deal of impact on the general equilibrium price elasticity of demand for energy in this particular shock. However, the slightly larger energy consumption does accompany a notably smaller increase in GDP compared to the base case scenario as the production mix shifts in favour of intermediates over labour and capital. 


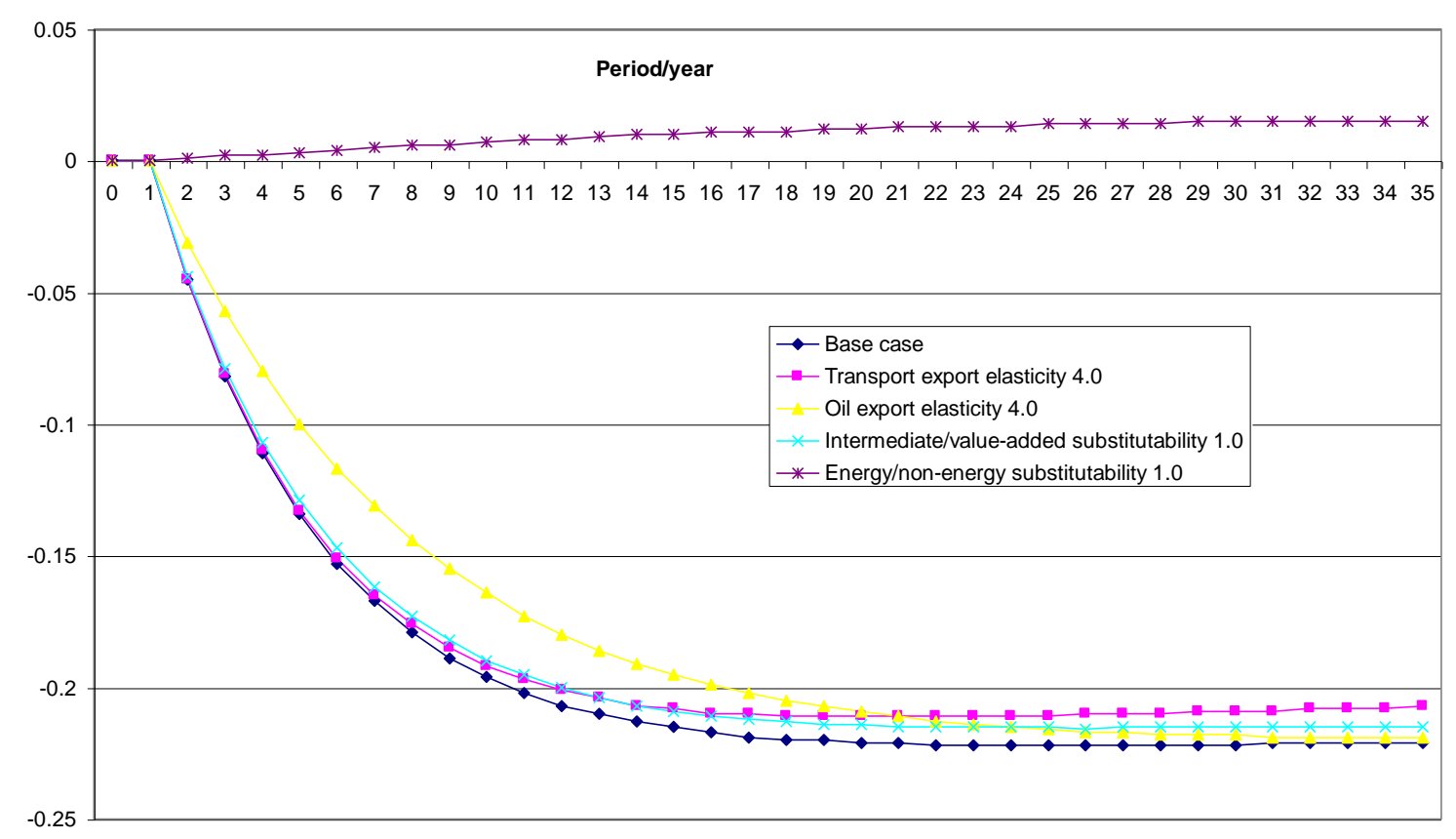

However, our final sensitivity test does have a significant impact. When we raise the value of the elasticity of substitution between energy and non-energy intermediates (to give us the energymaterials, or EM, composite in Figure 1) to unity, this one change alone (everything else in the model is specified as in the base case scenario/default configuration), is sufficient to (a) give us backfire effects in the oil rebound effect at the Transport sectoral and economy-wide level; (b) introduce sufficient price responsiveness that the drop in Oil sector revenues that triggers the disinvestment effect does not occur. In terms of the macroeconomic indicators, the results are mixed, slightly better than the previous scenario as the intermediate input mix shifts in favour of energy over non-energy inputs, but, again, worse than the base case due to the indirect substitution away from labour and value as energy demand becomes more price responsive. This latter point suggests that further research focussing on the specification of the KLEM production function, and, specifically the separability assumptions embodied in the decision regarding where energy should be introduced, is required. ${ }^{15}$

\section{Summary and Conclusions}

\footnotetext{
${ }^{15}$ We are currently engaged in research to incorporate different specifications of the KLEM nested production function into the AMOSENVI model; to econometrically test these specifications (for the case of the UK - see Footnote 7) and determine appropriate parameter values for key elasticities of substitution in production.
} 
The key focus of this study is the size of the economy-wide oil rebound effect from energy efficiency improvements within the Scottish commercial Transport industry. Our central case scenario returns a short-run sectoral level rebound effect of 36.4 and a long-run rebound effect of 39.2 for refined oil (as the main energy input to production in this sector) and economy-wide rebound effects of 36.5 in the short run and 38.3 in the long-run.

These results (for the sector-specific rebound effect in particular) are broadly consistent with estimates from partial equilibrium studies of rebound effects from increased energy efficiency in private and commercial transportation. In terms of non-CGE estimates of fuel price elasticities and rebound effects, Hanley et al (2002) derive figures equivalent to rebound effects of $25 \%$ and $64 \%$ in the short- and long-run respectively. Greene at al (1999) find a slightly smaller long-run rebound effect of about 20\%, whilst Sorrell's (2007) review suggested that "the long-run direct rebound effect for personal automotive transport lies somewhere between 10\% and 30\%" (op cit. p.31). Focussing on commercial transport activities, Gately (1988) carry out separate econometric analysis on the fuel price elasticity of HGVs and find a value equivalent to a direct rebound effect of $37 \%$, whilst Graham \& Glaister (2002) present a central range of $40-80 \%$ for freight traffic.

It is thought that the rebound effect should be smaller for commercial transport than for private transport as it is less sensitive to price (Hanley et al, 2002), whilst the economy-wide rebound effect should theoretically be greater than the direct rebound effect alone. As a result, the figures cited above can only be indicative of the kind of range that we may have expected our results to fall within. Nonetheless, the fact that the size of the rebound effects we have identified are of a similar magnitude to the range advocated by the established literature may be interpreted as lending additional support to its robustness. Moreover, as explained in Section 4.1, the changes in energy consumption in the simulations reported here are largely concentrated in the commercial Transport sector where the efficiency improvement in targeted.

However, the key general equilibrium effect in the results reported here is the presence of what Turner (2009) identifies as the 'disinvestment effect', here most notably in the Scottish (refined) Oil supply sector. While the long-run rebound effect is larger than the short-run value in all scenarios (in line with conventional theory about an expansion in the economy-wide production possibility frontier, as reflected in the theoretical rebound analyses of Wei, 2007, and Saunders, 2008), in our base case scenario, and most of our sensitivity analyses, it is only very slightly bigger. It is apparent here that in most cases the long-run rebound effects are significantly constrained by disinvestment effects reducing the productive capacity in the energy sectors, particularly the Scottish Oil sector. Such a contraction in capacity is not consistent with Wei's (2007) argument that long-run rebound effects will always be greater than short-run ones, and adds support to the findings of Turner $(2008,2009)$, 
who argues that disinvestment will constrain the long-run rebound effect in cases where there is not sufficient price responsiveness in the system to prevent falling actual energy prices to lead to decreases in revenue and profitability in local energy supply sectors. Under these circumstances, the return on capital will decline, triggering a contraction in capital stock. Only in one case presented here is the general equilibrium price elasticity of demand for energy found to be elastic (greater than unity), preventing the disinvestment effect from occurring and triggering backfire. However, Turner's (2008) previous analysis for Scotland, where the energy efficiency shock is more widely applied, found that disinvestment could occur in some energy supply sectors even in the presence of backfire.

The findings reported here emphasis the need for sensitivity analysis around key model parameters advocated by authors such as Washida (2004), Allan et al (2007), Sorrell (2007) and Turner (2008). The intention here is not to pass judgement on which parameter values are most realistic, but to identify which parameters themselves are the key drivers behind the results. A by-product of this is being able to tailor future empirical development of the model to the most influential areas. For example, the results presented here suggest that econometric estimation of both the structure of KLEM production functions at the sectoral level, and of the parameter values within, for example as demonstrated by Kemfert (1998) will be a valuable activity. 


\section{References}

Allan, G.J., Hanley, N.D., McGregor, P.G., Swales, J.K. and Turner, K.R. (2007) The impact of increased efficiency in the industrial use of energy: a computable general equilibrium analysis for the United Kingdom, Energy Economics, 29, pp. 779-798.

Allan, G.J., Gilmartin, M., McGregor, P.G., Swales, J.K. and Turner, K.R., (2008a), Modelling the economy-wide rebound effect, in Energy Efficiency and Sustainable Consumption: The Rebound Effect, Palgrave MacMillan.

Allan, G.J., Gilmartin, M., McGregor, P.G., Swales, J.K. and Turner, K.R., (2008b), Economics of energy efficiency, in J. Evans and L.C. Hunt, eds, International Handbook of Energy Economics, Edward Elgar, Cheltenham, UK, forthcoming.

Armington, P. (1969), A theory of demand for products distinguished by place of production, IMF

Staff Papers, 16, pp. 157-178.

Beauséjour, L., Lenjosek, G., and Smart, M. (1995) A GCE Approach to Modelling Carbon Dioxide Emissions Control in Canada and the United States, The World Economy, 18, pp.457-489.

Bergman, L. (1988) Energy Policy Modelling: a Survey of General Equilibrium Approaches, Journal of Policy Modelling, 10, pp.377-399.

Bergman, L. (1990) Energy and Environmental Constraints on Growth: a CGE Modelling Approach, Journal of Policy Modelling, 12, pp.671-691.

Birol, F. and Keppler J. H. (2000) Prices, technology development and the rebound effect, Energy Policy, 28, pp. 457-479.

Blanchflower, D.G. and Oswald, A.J. (1994), The Wage Curve, M.I.T. Press, Cambridge, Massachusetts.

Broadstock, D., Hunt, L. and Sorrell, S. (2007) Evidence from elasticity of substitution studies, in Sorrell, S. (ed) The Rebound effect: an assessment of the evidence for economy-wide energy savings from improved energy efficiency. UK Energy Research Centre.

Link: http://www.ukerc.ac.uk/Downloads/PDF/07/0710ReboundEffect/0710Techreport3.pdf. 
Brookes, L. (1990) The greenhouse effect: the fallacies in the energy efficiency solution, Energy Policy, 18, pp. 199-201

Dufournaud, C.M., Quinn, J.T. and Harrington, J.J. (1994), An applied general equilibrium (AGE) analysis of a policy designed to reduce the household consumption of wood in the Sudan, Resource and Energy Economics, 16, pp.69-90

Gately, D. (1990), “The U.S. demand for highway travel and motor fuel”, The Energy Journal, 11, pp. 59-73.

Glomsrød, S. and Taojuan, W. (2005), Coal cleaning: a viable strategy for reduced carbon emissions and improved environment in China?, Energy Policy, 33, pp.525-542

Graham, D. \& Glaister, S. (2002), Review of income and price elasticities of demand for road traffic, Centre for Transport Studies, Imperial College of Science, Technology and Medicine.

Greene, D.L, Kahn, J. \& Gibson, R. (1999), “An econometric analysis of the elasticity of vehicle travel with respect to fuel cost per mile using RTEC survey data" Oak Ridge National Laboratory, Oak Ridge, Tennessee

Grepperud, S. and Rasmussen, I. (2004), A general equilibrium assessment of rebound effects, Energy Economics, 26, pp.261-282

Hanley, M., Dargay, J.M. \& Goodwin, P.B. (2002) "Review of income and price elasticities in the demand for road traffic", ESRC Transport Studies Unit, University College London, London

Hanley N.D., McGregor P.G., Swales J.K., Turner K. (2006) The impact of a stimulus to energy efficiency on the economy and the environment: A regional computable general equilibrium analysis. Renewable Energy, 31; pp.161-171

Hanley N.D., McGregor P.G., Swales, J.K. and Turner, K. (2009) Do increases in energy efficiency improve environmental quality and sustainability?, Ecological Economics, 68, pp. 692-709. 
Harris, J.R. and Todaro, M. (1970), Migration, unemployment and development: a two-sector analysis, American Economic Review, 60, pp. 126-42.

Herring, H. (1999) Does energy efficiency save energy? The debate and its consequences, Applied Energy, 63, pp. 209-226.

Jevons, W.S. (1865) The coal question - can Britain survive?, first published in 1865, reprinted by MacMillan in 1906. (Relevant extracts appear in Environment and Changes, February, 1974)

Kemfert, C. (1998) Estimated substitution elasticities of a nested CES production function approach for Germany, Energy Economics, 20, pp. 249-264.

Khazzoom, D.J. (1980) Economic implications of mandated efficiency in standards for household appliances, Energy Journal, 1, pp. 21-39.

Layard, R., Nickell, S. and Jackman, R. (1991), Unemployment: Macroeconomic Performance and the Labour Market, Oxford University Press, Oxford.

Minford, P., Stoney, P., Riley, J. and Webb, B. (1994), An econometric model of Merseyside: validation and policy simulations, Regional Studies, 28, pp. 563-575.

Saunders, H.D. (1992) The Khazzoom-Brookes Postulate and Neoclassical Growth, The Energy Journal, 13, pp.131-148.

Saunders, H.D. (2000a) A view from the macro side: rebound, backfire and Khazzoom-Brookes, Energy Policy, 28, pp. 439-449.

Saunders, H.D. (2000b) Does predicted rebound depend upon distinguishing between energy and energy services?, Energy Policy, 28, pp. 497-500.

Saunders, H.D. (2008), "Fuel conserving (and using) production functions", forthcoming in Energy Economics, doi:10.1016/j/eneco.2007.11.006.

Schipper, L. (ed) (2000) On the rebound: the interaction of energy efficiency, energy use and economic activity, The Energy Journal (Special Issue), 28, pp. 6-7. 
Scottish Executive (2002) Input-Output Tables and Multipliers for Scotland 1999. Published by the Government Statistical Services. Download at http://www.scotland.gov.uk/input-output.

Semboja, H.H.H. (1994), The effects of an increase in energy efficiency on the Kenyan economy, Energy Policy, 22, pp.217-225

Sorrell, S. (2007), The rebound effect: an assessment of the evidence for economy-wide energy savings from improved energy efficiency, report produced by the UK Energy Research Centre. Download report at http://www.ukerc.ac.uk/Downloads/PDF/07/0710ReboundEffect.

Turner, K. (2003), A pilot study on constructing a Scottish sectoral CO2 emissions account, Fraser of Allander Institute Quarterly Economic Commentary, University of Strathclyde, vol. 28, No.3. pp.43-51.

Turner, K. (2008), A computable general equilibrium analysis of the relative price sensitivity required to induce rebound effects in response to an improvement in energy efficiency in the UK economy, Strathclyde Discussion Papers in Economics, No. 08-07.

Turner, K. (2009), Negative rebound and disinvestment effects in response to an improvement in energy efficiency in the UK Economy, forthcoming in Energy Economics, proofs in press doi:10:1016/j.eneco.2009.01.008. 2009.

Vikstrom, P. (2004), Energy efficiency and energy demand: a historical CGE investigation on the rebound effect in the Swedish economy 1957, paper presented at the International Input-Output Association conference on Input-Output and General Equilibrium Data, Modelling and Policy Analysis, Brussels, 2-4 September 2004.

Washida, T. (2004), Economy-wide model of rebound effect for environmental policy, paper presented at the International Workshop on Sustainable Consumption, University of Leeds, March $5^{\text {th }}-$ $6^{\text {th }} 2004$ and also presented at the ERE W3 conference, Kyoto, Japan, July 2006

Wei, T. (2007), Impact of energy efficiency gains on output and energy use with Cobb-Douglas production function, Energy Policy, 35, pp. 2023-2030. 


\section{Appendix 1. Sectoral breakdown of the 1999 Scottish AMOSENVI model}

\begin{tabular}{|c|c|c|}
\hline & & IOC \\
\hline 1 & AGRICULTURE & 1 \\
\hline 2 & FORESTRY PLANTING AND LOGGING & $2.1,2.2$ \\
\hline 3 & FISHING & 3.1 \\
\hline 4 & FISH FARMING & 3.2 \\
\hline 5 & Other mining and quarrying & 6,7 \\
\hline 6 & Oil and gas extraction & 5 \\
\hline 7 & Mfr food, drink and tobacco & 8 to 20 \\
\hline 8 & Mfr textiles and clothing & 21 to 30 \\
\hline 9 & Mfr chemicals etc & 36 to 45 \\
\hline 10 & $\begin{array}{l}\text { Mfr metal and non-metal goods } \\
\text { Mfr transport and other machinery, electrical and inst }\end{array}$ & 46 to 61 \\
\hline 11 & eng & 62 to 80 \\
\hline 12 & Other manufacturing & 31 to 34,81 to 84 \\
\hline 13 & Water & 87 \\
\hline 14 & Construction & 88 \\
\hline 15 & Distribution & 89 to 92 \\
\hline 16 & Transport & $\begin{array}{l}93 \text { to } 97 \\
98 \text { to } 107,109 \text { to }\end{array}$ \\
\hline 17 & Communications, finance and business & 114 \\
\hline 18 & $\mathrm{R} \& \mathrm{D}$ & 108 \\
\hline 19 & Education & 116 \\
\hline 20 & Public and other services & 115,117 to 123 \\
\hline & ENERGY & \\
\hline 21 & COAL (EXTRACTION) & 4 \\
\hline 22 & OIL (REFINING \& DISTR OIL AND NUCLEAR) & 35 \\
\hline 23 & GAS & 86 \\
\hline & ELECTRICITY & 85 \\
\hline 24 & Renewable (hydro and wind) & \\
\hline 25 & Non-renewable (coal, nuke and gas) & \\
\hline
\end{tabular}

